\title{
Effects of a Shuangling Fuzheng anticancer preparation on the proliferation of SGC-7901 cells and immune function in a cyclophosphamide-treated murine model
}

\author{
Hua-Sheng Chen, Jue Chen, De-Li Cui, Yuan-Yuan Zheng, Ai-Hua Xu, Gang Chen, Ling-Chang Jia
}

Hua-Sheng Chen, Jue Chen, De-Li Cui, Yuan-Yuan Zheng, Ai-Hua Xu, Gang Chen, Yangzhou University Medical College, Yangzhou 225001, Jiangsu Province, China

Ling-Chang Jia, Jiangsu Province Subei People Hospital,Yangzhou 225001, Jiangsu Province, China

Supported by The Society Development Research Programs of Foundation Science and Technology Department of Jiangsu Province, No. BS99382; the Science Basic Research Programs of University of Jiangsu Province, No. 06KJB360131

Correspondence to: Hua-Sheng Chen, Yangzhou University

Medical College, Yangzhou 225001, Jiangsu Province,

China. yzcwy050130@sina.com

Telephone: +86-514-87884241 Fax: +86-514-87341733

Received: June 30, $2007 \quad$ Revised: October 8, 2007

\begin{abstract}
AIM: To study the inhibitory effects of a Shuangling Fuzheng anticancer preparation (SFAP) on the human gastric cancer cell line SGC-7901 in vitro as well as its immune-modulated effects in a cyclophosphamide-treated murine model.
\end{abstract}

METHODS: MTT experiments and immunocytochemistry $A B C$ experiments were performed for detecting the proliferation of SGC-7901 cells in vitro and protein expression of c-myc. The staphylococcal protein A (SPA) rosette test was utilized for measuring the ratio of T-lymphocyte subsets from peripheral blood in a cyclophosphamide-treated murine model. Enzymelinked immunosorbant assay (ELISA) was performed for measuring the levels of serum sIL-2R in treated mice, while immunoturbidimetry was used for measuring the levels of immunoglobulins (Ig).

RESULTS: SFAP $(40-640 \mathrm{mg} / \mathrm{L}, 48 \mathrm{~h})$ inhibited the proliferation of SGC-7901 cells, and a positive correlation was noted between inhibitory effects and dosage. At a dosage of $160-320 \mathrm{mg} / \mathrm{L}$ in cultured cells, the expression of c-myc was decreased. SFAP $(50-200 \mathrm{mg} / \mathrm{kg})$ increased the percentage of $\mathrm{CD}^{+}$and $\mathrm{CD}^{+}{ }^{+}$-lymphocytes, the ratio of CD4/CD8, and the contents of Ig such as IgM, IgG or IgA, but decreased the levels of serum SIL-2R in peripheral blood from cyclophosphamide-treated mice.

CONCLUSION: SFAP can inhibit the proliferation of SGC-7901 cells via the c-myc gene. In addition, SFAP can modulat the cellular and humoral immunity in cyclophosphamide-induced immunosuppressed mice.

\section{(c) 2007 WJG. All rights reserved.}

Key words: Shuangling Fuzheng anticancer preparation; SGC-7901; Proliferation; c-myc; Immune function

Chen HS, Chen J, Cui DL, Zheng YY, Xu AH,Chen G, Jia LC. Effects of a Shuangling Fuzheng anticancer preparation on the proliferation of SGC-7901 cells and immune function in a cyclophosphamide-treated murine model. World J Gastroenterol 2007; 13(48): 6575-6580

http://www.wjgnet.com/1007-9327/13/6575.asp

\section{INTRODUCTION}

Shuangling Fuzheng anticancer preparation (SFAP) is made through the basic modification of Fuzheng anticancer granules (FAG). Clinical research has shown that FAG have a therapeutic effect for many tumor patients. An empirical study has shown that FAG can prolong the life of tumor-bearing mice and inhibit transplanted tumors. However, this inhibition ratio is lower than $30 \%{ }^{[1-3]}$. Modern pharmacologic studies have shown that atractylodes macrocephalae volatile oil ${ }^{[4]}$, coixenolide ${ }^{[5-7]}$, polysaccharides $^{[8,9]}$ and some other active constituents have anticancer activities. At the precondition of Chinese Medical Syndrome Differentiation, we extracted some of the effective anticancer constituents from FAG and developed SFAP. The main of making SFAP include extraction of volatile oils from atractylodes macrocephalae, coixenolide from coix seed, and polysaccharides from part of Fuzheng traditional Chinese medicines, boiling the other drugs with water as per the traditional method, and concentrating all constituents into a capsule preparation. The results of this experiment showed that the ratio of SFAP anticancer activity was significantly greater than $30 \% 0^{[10]}$. The present study reports the effects of SFAP on the proliferation of human gastric cancer cells and the expression of related genes in vitro, as well as its modulating effects on immune function in a cyclophosphamide-treated murine model.

\section{MATERIALS AND METHODS}

\section{Cell line and animals}

Human gastric cancer SGC-7901 cells, purchased from the Department of Cellular and Molecular Biology, Shanghai Institute of Biochemistry and Cell Biology, Academia 
Sinica, were cultured in vitro for 2-3 d. ICR mice (at the age of 6-7 wk, weighing 18-22 g; 50\% females) were obtained from Yangzhou University Medical Centre [animal production license number: SCXK (Su) 2002-0009].

\section{Drugs and reagents}

SFAP was made from Smilacis rhizome, Tuckahoe, honeyfried Astragalus mongholicus, Atractylodes macrocephala, coix seed, processed Pinelliae tuber, Aurantii nobilis pericarpium and the like. We extracted volatile oil from Atractylodes macrocephala, coixenolide from Coicis semen, and polysaccharides from other drugs by boiling in water. They are then mixed at the concentrations specified according to previous formulations. Lastly, the dried drugs were ground into coffee granules. An invention patent for the SFAP preparation protocol has been applied (application No.: 200610161699.5). SFAP was resuspended with RPMI 1640 (GibcoBRL, Maryland, USA) to a suitable dosage, filtrated, sterilized and stored at $4^{\circ} \mathrm{C}$ for testing in vitro. MT'T was from Sigma (St. Louis, MO, USA). Calf serum, trypsin (1:250), ABC immunohistochemical detection kit (concentrated type) and DAB substrate kit were from Huamei Biotechnology Company. Monoclonal mouse anti-human c-myc antibodies were provided by Huamei Biotechnology Company. Red blood cell rosette reagent used to restrain the monoclonal antibody hypersusceptibility to $\mathrm{CD} 3, \mathrm{CD} 4$ or $\mathrm{CD} 8$ from treated mice was from the Wuhan Biologic Product Institute. The soluble interleukin-2 receptor (sIL-2R) quantitative EIA kit was from Shanghai Senxiong Technology Industry Limited Company. Ig kit was obtained from Shanghai Sun Biological Products Co. Ltd. Injectible cyclophosphamide (CTX, batch number: 20051204) was obtained from Shanxi Jinde Medicine Limited Company. Ultrapure water was self-prepared. Other reagents were all analytical reagents made in China. Adriamycin was from Shenzhen Wanle Pharmaceutical Co. Ltd.

\section{MTT experiment}

SGC-7901 cells growing exponentially were digested with $2.5 \mathrm{~g} / \mathrm{L}$ trypsin, then washed several times with PBS ( $\mathrm{pH}$ 7.2). They were then counting and RPMI 1640 contained $100 \mathrm{~mL} / \mathrm{L}$ newborn bovine serum medium in order to adjust cell density to $1 \times 10^{8}$ cells $/ \mathrm{L}$. After the final cell suspensions were adjusted the to $100 \mu \mathrm{L} /$ well, 96-well plates were put into an incubator that containing $50 \mathrm{~mL} / \mathrm{L} \mathrm{CO}_{2}$, at $37^{\circ} \mathrm{C}$ for $24 \mathrm{~h}$. Then, $100 \mu \mathrm{L}$ RPMI 1640 containing different concentrations of SFAP (40-640 mg/L) was added to each well. Cells were cultured for $48 \mathrm{~h}$. Four hours before the end of culture, $100 \mu \mathrm{L}$ supernatant was removed and $10 \mu \mathrm{L}$ MTT (the final concentration was $5 \mathrm{~g} / \mathrm{L}$ ) was added and cultured for $4 \mathrm{~h}$, to which acid isopropyl alcohol was subsequently added per routine. The absorbance (A) for each well were measured at $570 \mathrm{~nm}$ with an ELISA reader. The inhibition ratios were calculated with the following formula: $(1$ - the mean of treated group/the mean of control group) $\times 100$.

\section{Immunohistochemical detection}

Cells were cultured as previously described and the cell density was adjusted to $2 \times 10^{8}$ cells/L. After the abovementioned cell suspensions were added to a $4 \mathrm{~mL}$ culture flask, the flask was placed into an incubator containing $50 \mathrm{~mL} / \mathrm{L} \mathrm{CO}_{2}$ at $37^{\circ} \mathrm{C}$ for $24 \mathrm{~h}$. Then, culture flasks were randomly divided into groups for different concentrations of SFAP (4 mL), and in the control group RPMI 1640 (4 mL) was added. After continuous culture for $48 \mathrm{~h}$, cells were isolated, digested, and washed. The cells were fixed with $40 \mathrm{~g} / \mathrm{L}$ formalin, imbedded with paraffin, and then consecutively sliced at a thickness of $3 \mu \mathrm{m}$. The paraffin slices were dewaxed and washed with graded alcohol, $3 \mathrm{~mL} / \mathrm{L} \mathrm{H}_{2} \mathrm{O}_{2}$ methanol, and incubated for $10 \mathrm{~min}$ at room temperature in order to inactivate the endogenous peroxidase activity and eliminate non-specific staining. Next, mouse anti-human c-myc monoclonal antibody attenuated at 1:100 was added, and incubated at $4{ }^{\circ} \mathrm{C}$ following the addition of biotinylated sheep anti-mouse IgG. After the above-mentioned mixture was incubated at $37^{\circ} \mathrm{C}$ in a moisture-saturated plastic chamber for $30 \mathrm{~min}$, ABC compound was added and incubation was continued for $30 \mathrm{~min}$, followed by three 5-min PBS washes. Staining with $\mathrm{DAB}$ was observed by microscope for 5-10 min, after which the cells were washed with tap water for $3 \mathrm{~min}$ in order to terminate the reaction. Finally, the slices were stained with haematoxylin, dehydrated, cleared, mounted and observed with a microscope. A light yellow cytolymph indicated positive expression of c-myc protein. Every slice was observed under five high power fields and each positive expression ratio was counted per the following formula: positive expression ratio $=$ (the sum of positive cells/the sum of all the cells) $\times 100 \%$.

\section{Influence on of SFAPT-Iymphocyte subsets from the peripheral blood}

The animal study protocol was approved by the Ethics Committee of Yangzhou University Medical College.

A total of 30 ICR mice, half being female, were randomly divided into five groups: NS group, CTX group and three (CTX + SFAP) treatment groups. The ICR mice in the NS group were treated ig and ip with 0.01 $\mathrm{mL} / \mathrm{g}$ normal saline (NS) once a day for $5 \mathrm{~d}$; the CTX group was treated ip with $40 \mathrm{mg} / \mathrm{kg}$ CTX and ig with NS once a day for $5 \mathrm{~d}$; three (CTX + SFAP) treatment groups were treated ip with CTX $40 \mathrm{mg} / \mathrm{kg}$ and $i g$ with SFAP, such that the dose was 50,100 or $200 \mathrm{mg} / \mathrm{kg}$ SFAP once a day for $5 \mathrm{~d}$. The Staphylococcal protein A (SPA) rosette test was utilized on the sixth day for measuring the ratio of T-lymphocyte subsets from peripheral blood. The eyes of the mice were removed and venous blood was gathered (about $1 \mathrm{~mL}$ ), which was then placed into an anticoagulated heparin test tube. One milliliter of NS was added to the test tube. After mixing, $2 \mathrm{~mL}$ of T-lymphocyte cell separating medium was added, and then the blood sample was centrifuged for $15 \mathrm{~min}$ at 3000 $\mathrm{r} / \mathrm{min}$. The intermediate buffy coat was collected and washed three times with Hank's solution. The number of T-lymphocytes was then adjusted to $1000 / \mathrm{mm}^{3}$. The intermediate lymphocyte suspension $(10 \mu \mathrm{L})$ was placed into three test tubes and $10 \mu \mathrm{L}$ of the red blood cell suspension was added to each tube in order to restrain monoclonal antibody hypersusceptibility of CD3, CD4 or CD8 in mice. After incubating the above-mentioned suspension at $37^{\circ} \mathrm{C}$ for $30 \mathrm{~min}$, it was centrifuged for 
Table 1 Inhibitory effect of SFAP on proliferation of SGC-7901 cells (mean \pm SD)

\begin{tabular}{lclc}
\hline Group & Dose $\mathbf{( m g / L )}$ & A value & Rate Inhibition (\%) \\
\hline Control & 0 & $0.290 \pm 0.027$ & 0 \\
SFAP & 40 & $0.248 \pm 0.055$ & 14.5 \\
SFAP & 80 & $0.239 \pm 0.044$ & 17.6 \\
SFAP & 160 & $0.230 \pm 0.034$ & 20.7 \\
SFAP & 320 & $0.220 \pm 0.041^{\mathrm{a}}$ & 24.1 \\
SFAP & 640 & $0.212 \pm 0.009^{\mathrm{b}}$ & 26.9 \\
Adriamycin & 2 & $0.125 \pm 0.037^{\mathrm{b}}$ & 56.9 \\
\hline
\end{tabular}

${ }^{\mathrm{a}} P<0.05,{ }^{\mathrm{b}} P<0.01$ vs Control.

Table 2 Influence of SFAP on expression of c-myc protein in SGC-7901 cells (mean \pm SD)

\begin{tabular}{lcc}
\hline Group & Dose $(\mathbf{m g} / \mathbf{L})$ & Positive c-myc rate $(\%)$ \\
\hline Control & 0 & $22 \pm 6$ \\
SFAP & 160 & $11 \pm 3^{\mathrm{b}}$ \\
SFAP & 320 & $9 \pm 3^{\mathrm{b}}$ \\
\hline
\end{tabular}

${ }^{\mathrm{b}} \mathrm{P}<0.01$ vs control.

$3 \mathrm{~min}$ at $1000 \mathrm{r} / \mathrm{min}$, made into a slice, dried, and was colored with Gliemsa solution for $30 \mathrm{~min}$. The number of cells positive for CD3, CD4 or CD8 were then observed through a microscope. A T-lymphocytes binding with more than 3 red cells (rosette formation) was defined as positive. More than 200 T-lymphocyte were counted, and the percentage of cells with rosette formation was calculated.

\section{Influence on serum sIL-2R contents}

As described above, ICR mice were grouped and treated; in this case, the dose of CTX administered was $10 \mathrm{mg} / \mathrm{kg}$. The eyes were removed, venous blood was gathered (about $1 \mathrm{~mL}$ ) and blood serum was centrifuged on the sixth day. Per kit instructions, ELISA was used to measure the levels of sIL-2R from blood serum in treated mice. The sample dilution $(50 \mu \mathrm{L})$ and the solution awaiting detection $(50 \mu \mathrm{L})$ were put into each well of the reaction plate. After mixing, the reaction plate was stored at $37^{\circ} \mathrm{C}$ for $2 \mathrm{~h}$, and was subsequently washed 4-6 times and blotted on filter paper. The first antibody $(100 \mu \mathrm{L})$ was placed into each well, the reaction plate was stored at $37^{\circ} \mathrm{C}$ for $1 \mathrm{~h}$, and then washed as described above. The enzyme-labeled antibody $(100 \mu \mathrm{L})$ was placed in each well and was stored at $37^{\circ} \mathrm{C}$ for $1 \mathrm{~h}$; the reaction plate was then washed as described above. The substrate $(100 \mu \mathrm{L})$ was placed into each well, and was allowed to react for $5-10 \mathrm{~min}$ in the dark at $37^{\circ} \mathrm{C}$. Lastly, one drop of stop buffer was put in each well and mixed, from which absorption was then detected at 492 $\mathrm{nm}$. The levels of sIL-2R were determined according to the standard curve of absorption-concentration.

\section{Influence on serum Ig contents}

As described above, the dose of CTX was changed to $10 \mathrm{mg} / \mathrm{kg}$. Immunoturbidimetry was utilized for measuring the levels of $\mathrm{Ig}$ from blood serum in mice on the sixth
Table 3 Influence of SFAP on T-Iymphocyte subsets from peripheral blood in cyclophosphamide-treated mice

\begin{tabular}{lcllll}
\hline Group & Dose (mg/kg) & CD3 (\%) & CD4 (\%) & CD8 (\%) & CD4/CD8 \\
\hline NS control & 0 & $46.2 \pm 4.5$ & $28.5 \pm 1.4$ & $17.7 \pm 2.16$ & $1.6 \pm 0.1$ \\
CTX control & 40 & $37.5 \pm 2.4^{\mathrm{b}}$ & $21.5 \pm 2.2^{\mathrm{b}}$ & $16.3 \pm 1.6$ & $1.3 \pm 0.1^{\mathrm{b}}$ \\
SFAP + CTX & $50+40$ & $38.7 \pm 2.2$ & $22.2 \pm 2.3$ & $16.7 \pm 2.0$ & $1.3 \pm 0.2$ \\
SFAP + CTX & $100+40$ & $39.7 \pm 3.1$ & $24.2 \pm 2.3$ & $16.2 \pm 1.5$ & $1.5 \pm 0.1^{\mathrm{c}}$ \\
SFAP + CTX & $200+40$ & $42.3 \pm 2.5^{\mathrm{d}}$ & $26.7 \pm 2.3^{\mathrm{d}}$ & $16.8 \pm 1.5$ & $1.6 \pm 0.1^{\mathrm{d}}$ \\
\hline
\end{tabular}

${ }^{\mathrm{b}} P<0.01$ vs NS control; ${ }^{\mathrm{c}} P<0.05,{ }^{\mathrm{d}} P<0.01$ vs $\mathrm{CTX}$ control group.

day. The eyes were removed, venous blood was collected $(1 \mathrm{~mL})$, and the sample was centrifuged. The diluted blood serum $(40 \mu \mathrm{L}, 10 \mu \mathrm{L}$ or $80 \mu \mathrm{L})$ was put into a test tube, and $1 \mathrm{~mL} \operatorname{IgA}, \operatorname{IgG}$ or IgM was added to each tube. After mixing, the samples were immersed in a water bath at $37^{\circ} \mathrm{C}$ for $15 \mathrm{~min}$, a semi-automatic biochemistry analyzer zero was adjusted to $340 \mathrm{~nm}$ with NS, and the absorption for each test was detected. The levels of $\operatorname{IgA}, \operatorname{IgG}$ or $\operatorname{IgM}$ were computed according to the absorption-concentration standard curve.

\section{Statistical analysis}

Data are presented as the mean \pm SD for all experiments. Comparisons of numerical data were performed using the $t$ test, and comparisons of categorical data were performed using $\chi^{2}$ test.

\section{RESULTS}

\section{Effect of SFAP on proliferation of SGC-7901 cells}

SFAP (40-640 mg/L, $48 \mathrm{~h}$ ) inhibited proliferation of SGC-7901 cells in a dose-dependent manner. This effect was statistically significant at dosages of $160 \mathrm{mg} / \mathrm{L}$ and $320 \mathrm{mg} / \mathrm{L}$ (Table 1).

\section{Effect of SFAP on c-myc protein expression in SGC-7901 cells}

SFAP decreased the expression of c-myc protein in SGC-7901. This was statistically significant when compared with the control group (Table 2).

\section{Effect of SFAP on distribution of T-lymphocyte subsets from the peripheral blood in mice}

CTX $\left(40 \mathrm{mg} / \mathrm{kg}\right.$ ) decreased the percentage of $\mathrm{CD}^{+}$and $\mathrm{CD}^{+}$T-lymphocytes and the ratio of CD4/CD8 from the peripheral blood, which was statistically significant compared with the control group. The percentage of the $\mathrm{CD}^{+}$and $\mathrm{CD}^{+}{ }^{+}$-lymphocytes was increased in all three SFAP dosage groups (50, 100 or $200 \mathrm{mg} / \mathrm{kg}$ ), with the difference being statisticall significanct in the largest dosage group (200 mg/kg), compared with the CTX group. The moderate and largest dosage groups (100 and $200 \mathrm{mg} / \mathrm{kg}$, respectively) increased the ratio of $\mathrm{CD} 4 / \mathrm{CD} 8$ from the peripheral blood, and this was statistically significant compared with the CTX group (Table 3).

\section{Effect of SFAP on serum sIL-2R and Ig contents}

CTX $(10 \mathrm{mg} / \mathrm{kg}$ ) increased the levels of sIL-2R in the serum, which was highly significantly different compared with the NS control group $(P<0.01)$. Both moderate and largest dosage 
Table 4 Influence of SFAP on serum sIL-2R and Ig levels in cyclophosphamide-treated mice (mean \pm SD)

\begin{tabular}{lcllll}
\hline Group & Dose $(\mathbf{m g} / \mathbf{k g})$ & slL-2R $(\mathbf{p m o l} / \mathbf{L})$ & $\operatorname{IgA}(\mathbf{g} / \mathbf{L})$ & $\operatorname{IgG}(\mathbf{g} / \mathbf{L})$ & IgM(g/L) \\
\hline NS control & 0 & $30.4 \pm 2.5$ & $2.92 \pm 0.84$ & $8.07 \pm 0.94$ & $2.31 \pm 0.51$ \\
CTX control & 10 & $77.8 \pm 8.5^{\mathrm{b}}$ & $1.77 \pm 0.14^{\mathrm{b}}$ & $6.35 \pm 0.63^{\mathrm{b}}$ & $1.68 \pm 0.14^{\mathrm{a}}$ \\
SFAP + CTX & $50+10$ & $75.9 \pm 6.4$ & $2.02 \pm 0.31$ & $6.87 \pm 0.34$ & $1.82 \pm 0.27$ \\
SFAP + CTX & $100+10$ & $59.6 \pm 6.1^{\mathrm{d}}$ & $2.31 \pm 0.48^{\mathrm{c}}$ & $7.70 \pm 0.37^{\mathrm{d}}$ & $2.16 \pm 0.33^{\mathrm{d}}$ \\
SFAP + CTX & $200+10$ & $52.7 \pm 5.7^{\mathrm{d}}$ & $3.11 \pm 0.72^{\mathrm{d}}$ & $7.87 \pm 0.59^{\mathrm{d}}$ & $2.49 \pm 0.46^{\mathrm{d}}$ \\
\hline
\end{tabular}

${ }^{\mathrm{a}} P<0.05,{ }^{\mathrm{b}} P<0.01$ vs NS control ${ }^{\mathrm{c}} P<0.05,{ }^{\mathrm{d}} P<0.01$ vs CTX control.

groups (100 mg/ $\mathrm{kg}$ and $200 \mathrm{mg} / \mathrm{kg}$ ) decreased the levels of sIL-2R in serum from mice treated with cyclophosphamide, which was statistically significant compared with the CTX group (Table 4). In addition, CTX $(10 \mathrm{mg} / \mathrm{kg})$ inhibited the elaboration of Ig, and was significantly different compared with the NS control group. All three SFAP groups increased the levels of $\operatorname{IgA}$, $\operatorname{Ig} G$ and $\operatorname{IgM}$ in the serum when induced by cyclophosphamide, with statistical significance for the large and moderate dose groups when compared with the CTX control group (Table 4).

\section{DISCUSSION}

The target cells in this study were from the cell line SGC-7901. After culturing in vitro for $48 \mathrm{~h}$, MTT experiments were utilized to detect SGC-7901 proliferation in vitro. The results proved that SFAP $(40-640 \mathrm{mg} / \mathrm{L})$ inhibited the proliferation of SGC-7901 and the correlation between the inhibitory effects and the dosage was positive, such that there was a dose-effect relationship. From this observation, we postulate that SFAP directly inhibits the proliferation of SGC-7901 cells. The c-myc protein is the key to controlling the proliferation of these cells, and has been shown to induce tumor cells into multiplication cycles and promote hyperplasia ${ }^{[11-14]}$. We utilized the immunocytochemistry ABC experiment to detect the influence of SFAP on protein expression of c-myc in SGC-7901 cells. The results proved that SFAP (40-640 mg/L) decreased protein expression of c-myc in these cells. These data imply that c-myc probably affects the regulation of tumor cell proliferation. Considerable evidence has demonstrated that when immunomodulatory mechanisms are suppressed, the incidence rate of the tumor increases and the speed of cancer metastasis and growth quickens. When the malignancy grows constantly or radiotherapy and/or chemotherapy are applied to manage the tumor, the immunomodulatory mechansisms of the patient decline. Thus, there is a close relationship between immunomodulatory activity and the appearance of cancer ${ }^{[15-18]}$

Cellular immunity is the key to host tumor immunity, and T-lymphocytes are the critical immune component for tumor immunity. The cluster differentiation (CD) antigen is an important immune cell membrane molecule. CD3 antigen is present on the cell membrane of all mature T-lymphocytes in the peripheral blood and is involved in $\mathrm{CD}^{+}$and $\mathrm{CD}^{+}{ }^{+}$-lymphocyte response. The former is mainly a helper T-lymphocyte, which can also assist B cells to generate antibodies, and the later is chiefly a suppressor T-lymphocyte which can release suppressive cytokines to suppress cellular and humoral immune responses. When T-lymphocyte-mediated cellular immunity is weakened, CD4 is decreased while CD8 is increased, thus the ratio of $\mathrm{CD} 4 / \mathrm{CD} 8$ decreases ${ }^{[19-23]}$. Our experimental results show that SFAP treatment at all used dosages increased the percentage of $\mathrm{CD}^{+}$cells in the CTX mouse model, and at the same time increased the ratio of CD4/CD8. IL-2 is an important immune factor secreted by helper T-lymphocytes, which after combining with IL-2R could promote immune cell proliferation and suppress tumor cell division. sIL$2 \mathrm{R}$ derives mainly from active T-lymphocyte membrane receptor proteins which could competitively bind to IL-2, thereby restraining the biological activity of IL-2. Thus, sIL$2 \mathrm{R}$ is regarded as an important immune suppressor ${ }^{[24-28]}$. The experimental results in the present study show that SFAP significantly decreased the level of sIL-2R in a CTX mouce model, which suggests that SFAP could enhance cellular immune function in mice inhibited by CTX.

Humoral immunity is critical to host tumor immunity ${ }^{[29]}$. For example, a variety of antibodies from the blood promote effector cells to recognize and kill tumor cells. Our results show that SFAP is capable of enhancing humoral immune function in mice inhibited by CTX by increasing the serum levels of $\mathrm{IgA}, \mathrm{IgG}$ and $\mathrm{IgM}$.

Many traditional Chinese medicines derived from the Fuzheng drug are capable of enhancing immune function with few adverse effects; however, the amount of tumor death is small. Traditional cytotoxic drugs are powerful enough to kill tumor cells, but they come with high toxicity, especially with regards to immune and hemotologic function ${ }^{[30]}$. Thus, many doctors avoid using these kinds of drugs to their patients. The results of our experiments show that SFAP directly inhibits the proliferation of SGC-7901 cells and enhances the cellular and humoral immune function inhibited by CTX. These effects may be beneficial for cancer prevention, anti-cancer therapies, prevention of cancer relapse and metastasis, and avoidance of adverse reactions from radiotherapy and chemotherapy.

\section{ACKNOWLEDGMENTS}

We thank Dr. Xiao-Ling Wang for his technical assistance in the preparation of this manuscript.

\section{COMMENTS}

\section{Background}

Malignant tumors are one of the most common causes of mortality in China and the world. While surgical treatment predominates in comprehensive therapy 
for tumors, anti-tumor drugs still play an important role. Currently, cytotoxic compounds remain the major constituent of chemotherapy drugs. However, cytotoxic compounds have poor therapeutic effects on the solid tumors and generate higher toxic side-effects and drug resistance. Many Chinese traditional medicines can enhance the immune function of the host, with few toxic side-effects when used in the treatment of tumors.

\section{Research frontiers}

Shuangling Fuzheng anticancer preparation (SFAP) consists of Fuzheng and Quxie Chinese traditional medicines. SFAP directly inhibits the proliferation of cancer cells through the action of Fuzheng, and also promotes cellular and humoral immune function in a cyclophosphamide-treatment mouse model through its Quxie action.

\section{Innovations and breakthroughs}

Fuzheng anticancer granules (FAG) promote immune function and inhibit transplanted tumors in mice, but the inhibition rate is less than $30 \%$. SFAP has the same constituents of FAG, but improves the action of FAG. At the precondition of Chinese Medical Syndrome Differentiation, the main characteristics of SFAP production were extraction of volatile oils from Atractylodes macrocephalae, coixenolide from coix seed, and polysaccharides from part of Fuzheng traditional Chinese medicines, boiling the other drugs with water as per the traditional method, and concentrating all constituents into a capsule preparation. The results of this experiment showed that the ratio of SFAP anticancer activity was significantly greater than $30 \%$. Moreover, SFAP could directly inhibit the proliferation of the cancer cells in vitro, and also promote immune function in cyclophosphamide-treated immunosuppressive mice.

\section{Applications}

The immune function of the human body has a close association with the development of cancer. On the one hand, when immune function is suppressed, the incidence of cancer increases and the speed of cancer metastasis quickens. On the other hand, when the malignancy grows constantly in vivo or radiotherapy or chemotherapy is given to cancer patients, immune function declines as the state of illness worsens. SFAP could directly control tumor cell growth and adjust the balance of cellular and humoral immunity of human body under different conditions. It exerts not only Fuzheng action, but also Quxie action. SFAP may be beneficial for all cancer patients and of applications in cancer prevention, anticancer therapy with few adverse reactions.

\section{Peer review}

The Chinese traditional medicine constituents of SFAP are logical and scientific. Its preparation process has many salient features. The preparation exerts not only Fuzheng action, but also Quxie action. The inhibition ratio of SFAP on tumor is higher than common Chinese traditional medicine, and the toxic sideeffects are less than those of conventional anti-tumor chemotherapy drugs. As a new compound for anti-tumor therapy, SFAP should be developed as soon as possible.

\section{REFERENCES}

1 Chen HS, Xu AH, Xiang XR, Zhang BS, Zhai F. Experimental Studies on Antitumour Action of Fuzheng Kangai Granule. Zhongyao Xinyao yu Linchuang Yaoli 1995; 6: 27-31

2 Chen HS, Zhai F, Zhou DT, Chen GY. 32 Cases of Digestive Tract Tumors of Middle and Late Stage Treated with Fuzhen Anticancer Decoction. Liaoning zhongyi Zazhi 1995; 22: 362-363

3 Zhai F, Chen HS. The Clinical Observation of the Patients with Digestive Tract Tumors of Middle and Late Stage Treated by Fuzhenkangai Decoction. Zhongguo Zhongxiyi Jiehe Piwei Zazhi 1997; 5: 67-69

4 Wang X, Liu YY, Shi TL, Zhang HX, Yang GW. Inhibitory activity of volatile oil from Atractylodes macrocephala Koidz. on parenchymatous tumor in mice. Zhongguo Yaowu Yu Lingchuang 2002; 2:239-240

5 Hu XK, Li Y, Wu DH, Hu ZG, Liang CS. The Sensitizing Enhancement Effect of Coixenolide on the Irradiation to Human Nasopharyngeal Carcinoma Cell CNE-2Z. Zhongshan Yike Daxue Xuebao 2000; 21: 334-336

6 Hu AJ, Zhao S, Liang H, Qiu TQ, Chen G. Ultrasound assisted supercritical fluid extraction of oil and coixenolide from adlay seed. Ultrason Sonochem 2007; 14: 219-224

7 Kaneda T, Hidaka Y, Kashiwai T, Tada H, Takano T, Nishiyama S, Amino N, Miyai K. [Effect of coix seed on the changes in peripheral lymphocyte subsets]. Rinsho Byori 1992; 40: $179-181$

8 Chen HS, Ren L, Xu AH, Lu P. [Study on the comparison of polysaccharides in Ginkgo biloba leaves]. Zhongyaocai 2006; 29 : 1139-1141

9 Wang J, Ito H, Shimura K. Enhancing effect of antitumor polysaccharide from Astragalus or Radix hedysarum on C3 cleavage production of macrophages in mice. Jpn J Pharmacol 1989; 51: 432-434

10 Chen HS, Xu AH, Wang ZB, Jia LC, Zhai F. Experimental Study of Shuang Ling Fuzheng Kangai Capsule(SLFKC) on Inhibiting Heps of Mouse. Zhongguo Shiyan Fangjixue Zazhi 2003; 9: 45-46, 48

11 Chen JP, Lin C, Xu CP, Zhang XY, Fu M, Deng YP, Wei Y, $\mathrm{Wu} \mathrm{M}$. Molecular therapy with recombinant antisense c-myc adenovirus for human gastric carcinoma cells in vitro and in vivo. J Gastroenterol Hepatol 2001; 16: 22-28

12 Liu H, Lo CR, Jones BE, Pradhan Z, Srinivasan A, Valentino KL, Stockert RJ, Czaja MJ. Inhibition of c-Myc expression sensitizes hepatocytes to tumor necrosis factor-induced apoptosis and necrosis. J Biol Chem 2000; 275: 40155-40162

13 Zhu GH, Wong BC, Eggo MC, Ching CK, Yuen ST, Chan EY, Lai KC, Lam SK. Non-steroidal anti-inflammatory druginduced apoptosis in gastric cancer cells is blocked by protein kinase $\mathrm{C}$ activation through inhibition of c-myc. $\mathrm{Br} J$ Cancer 1999; 79: 393-400

14 Ishii HH, Gobé GC, Pan W, Yoneyama J, Ebihara Y. Apoptosis and cell proliferation in the development of gastric carcinomas: associations with c-myc and p53 protein expression. J Gastroenterol Hepatol 2002; 17: 966-972

15 Yao JC, Mansfield PF, Pisters PW, Feig BW, Janjan NA, Crane C, Ajani JA. Combined-modality therapy for gastric cancer. Semin Surg Oncol 2003; 21: 223-227

16 Xiong HQ, Gunderson LL, Yao J, Ajani JA. Chemoradiation for resectable gastric cancer. Lancet Oncol 2003; 4: 498-505

17 Gao X, Xu YX, Janakiraman N, Chapman RA, Gautam SC. Immunomodulatory activity of resveratrol: suppression of lymphocyte proliferation, development of cell-mediated cytotoxicity, and cytokine production. Biochem Pharmacol 2001; 62: 1299-1308

18 Ueda Y, Yamagishi H, Tanioka Y, Fujiwara H, Fuji N, Itoh T, Fujiki H, Yoshimura T, Oka T. Clinical application of adoptive immunotherapy and IL-2 for the treatment of advanced digestive tract cancer. Hepatogastroenterology 1999; 46 Suppl 1: 1274-1279

19 Schepers K, Toebes M, Sotthewes G, Vyth-Dreese FA, Dellemijn TA, Melief CJ, Ossendorp F, Schumacher TN. Differential kinetics of antigen-specific CD4+ and CD8+ T cell responses in the regression of retrovirus-induced sarcomas. $J$ Immunol 2002; 169: 3191-3199

20 Zwaveling S, Vierboom MP, Ferreira Mota SC, Hendriks JA, Ooms ME, Sutmuller RP, Franken KL, Nijman HW, Ossendorp F, Van Der Burg SH, Offringa R, Melief CJ. Antitumor efficacy of wild-type p53-specific CD4(+) T-helper cells. Cancer Res 2002; 62: 6187-6193

21 Schuurhuis DH, van Montfoort N, Ioan-Facsinay A, Jiawan R, Camps M, Nouta J, Melief CJ, Verbeek JS, Ossendorp F. Immune complex-loaded dendritic cells are superior to soluble immune complexes as antitumor vaccine. J Immunol 2006; 176: 4573-4580

22 Diederichsen AC, Hjelmborg Jv, Christensen PB, Zeuthen J, Fenger C. Prognostic value of the CD4+/CD8+ ratio of tumour infiltrating lymphocytes in colorectal cancer and HLA-DR expression on tumour cells. Cancer Immunol Immunother 2003; 52: $423-428$

23 Velders MP, Markiewicz MA, Eiben GL, Kast WM. CD4+ T cell matters in tumor immunity. Int Rev Immunol 2003; 22: 113-140

24 Sakata H, Murakami S, Hirayama R. Serum soluble interleukin-2 receptor (IL-2R) and immunohistochemical 
staining of IL-2R/Tac antigen in colorectal cancer. Int J Clin Oncol 2002; 7: 312-317

25 Sasada T, Kimura M, Yoshida Y, Kanai M, Takabayashi A. CD4+CD25+ regulatory $T$ cells in patients with gastrointestinal malignancies: possible involvement of regulatory $\mathrm{T}$ cells in disease progression. Cancer 2003; 98: 1089-1099

26 Murakami S, Sakata H, Tsuji Y, Okubo K, Hamada S, Hirayama R. Serum soluble interleukin-2 receptor as a predictor of lymph node metastasis in early gastric cancer. Dig Surg 2002; 19: 9-13; discussion 14

27 Hadden JW. The immunology and immunotherapy of breast cancer: an update. Int J Immunopharmacol 1999; 21: 79-101

28 Hadden JW, Saha A, Sosa M, Hadden EM. Immunotherapy with natural interleukins and/or thymosin alpha 1 potently augments T-lymphocyte responses of hydrocortisone-treated aged mice. Int J Immunopharmacol 1995; 17: 821-828

29 Hadden JW. Immunodeficiency and cancer: prospects for correction. Int Immunopharmacol 2003; 3: 1061-1071

30 Xu AH, Chen HS, Sun BC, Xiang XR, Chu YF, Zhai F, Jia LC. Therapeutic mechanism of ginkgo biloba exocarp polysaccharides on gastric cancer. World J Gastroenterol 2003; 9: 2424-2427

S- Editor Ma N L- Editor Wang XL E- Editor Wang HF 